\title{
Who experiences discrimination in Brazil? Evidence from a large metropolitan region
}

\author{
James Macinko ${ }^{*}$, Pricila Mullachery ${ }^{1}$, Fernando A Proietti ${ }^{2}$ and Maria Fernanda Lima-Costa ${ }^{2,3}$
}

\begin{abstract}
Introduction: Perceived discrimination is related to poor health and has been offered as one explanation for the persistence of health inequalities in some societies. In this study, we explore the prevalence and correlates of perceived discrimination in a large, multiracial Brazilian metropolitan area.

Methods: The study uses secondary analysis of a regionally representative household survey conducted in 2010 $(n=12,213)$. Bivariate analyses and multiple logistic regression assess the magnitude and statistical significance of covariates associated with reports of any discrimination and with discrimination in specific settings, including when seeking healthcare services, in the work environment, in the family, in social occasions among friends or in public places, or in other situations.

Results: Nearly $9 \%$ of the sample reported some type of discrimination. In multivariable models, reports of any discrimination were higher among people who identify as black versus white (OR 1.91), higher (OR 1.21) among women than men, higher (OR 1.33) among people in their 30's and lower (OR 0.63) among older individuals. People with many health problems (OR 4.97) were more likely to report discrimination than those with few health problems. Subjective social status (OR 1.23) and low social trust (OR 1.27) were additional associated factors. Perceived discrimination experienced while seeking healthcare differed from all other types of discrimination, in that it was not associated with skin color, social status or trust, but was associated with sex, poverty, and poor health.
\end{abstract}

Conclusions: There appear to be multiple factors associated with perceived discrimination in this population that may affect health. Policies and programs aimed at reducing discrimination in Brazil will likely need to address this wider set of interrelated risk factors across different populations.

Keywords: Discrimination, Brazil

\section{Introduction}

Experiences of discrimination, defined as manifestation of negative attitudes, judgments, or differential treatment on the basis of gender, race, social class, or other characteristics that disadvantages a social group,[1] have emerged as an important cause of poor health and one explanation for the persistence of health inequalities in some societies [2-7]. Discrimination is believed to contribute to poor mental and physical health through several pathways, including structural factors such as differential rates of arrest and incarceration, disparities in wages, unequal educational and housing opportunities,

\footnotetext{
* Correspondence: james.macinko@nyu.edu

${ }^{1}$ Dept. of Nutrition, Food Studies \& Public Health, New York University, New York, USA

Full list of author information is available at the end of the article
}

and unequal access to and treatment in social services $[3,5,8,9]$. Additional evidence points to biological mechanisms linking discrimination with cumulative exposure to stress and subsequent deterioration of mental and physical health status and the emergence of additional risk factors [10-12]. Relationships between perceived discrimination and health have also been identified through differences in access to and use of health services, and through coping strategies that may result in less than optimal health behaviors [13-17].

Much of the existing literature-often focusing on discrimination based on the victim's perceived race or skin color-comes from the United States [12]. Research points to a set of underlying mechanisms that may link experiencing discrimination with health inequalities, but
C Biomed Central

(c) 2012 Macinko et al.; licensee BioMed Central Ltd. This is an Open Access article distributed under the terms of the Creative Commons Attribution License (http://creativecommons.org/licenses/by/2.0), which permits unrestricted use, distribution, and reproduction in any medium, provided the original work is properly cited. 
there is much to be learned about how different risk factors for experiencing discrimination may interrelate and how they may differ in different settings $[7,15,16,18]$. For these reasons, cross-national studies on discrimination and health can be helpful in understanding how and where discrimination occurs, identifying risk and protective factors, and developing mechanisms to mitigate the negative impacts of discrimination on health.

The study of discrimination in Brazil may be particularly fruitful, given the country's large, multi-racial population, complex race and social relations, and considerable social and economic diversity. In Brazil, studies on perceived discrimination point to the importance of key demographic characteristics such as skin color, socio-economic status (SES), and gender. Existing studies suggest that people who describe their skin color as other than white, women, less educated individuals, and sexual minorities are more likely to report having experienced some sort of discrimination [19-22]. The literature has also documented differences in access to health care and quality of care received by different underprivileged groups in society. For example, black and poor women have reduced access to antenatal care and low quality postnatal care $[14,16]$. Other studies revealed significant differences in coverage of clinical breast examination based on SES and skin color [15]. In terms of health outcomes, Brazilian studies have found positive correlations between self-reported discrimination and poor self-rated health as well as adverse health behaviors [19,23-25]. In a nationally-representative survey, nearly one tenth of recent users of outpatient health services reported feeling that they had been victims of some type of discrimination [20].

This paper contributes to the discussion of discrimination and health by exploring the prevalence and correlates of self-reported discrimination, based on a recent representative sample of a large metropolitan region in Brazil. Our objective is to gain better understanding of the distribution, relative magnitude, and interrelationships among risk factors for exposure to discrimination within a large, multiracial, metropolitan area.

\section{Methods}

The study took place in the Belo Horizonte Metropolitan Region, which includes the city of Belo Horizonte (the capital of the state of Minas Gerais and home to 2.4 million inhabitants) and about 2 dozen surrounding municipalities. The total population in the region is nearly 5 million inhabitants [26]. Although the city has Brazil's fourth largest GDP and a high Human Development index (0.84), it has large inequalities in health and socioeconomic conditions [27].

We use data from the second Household Health Survey of the Metropolitan Region of Belo Horizonte conducted in July 2010. Data collection was carried out via a supplement to the Regional Employment and Unemployment Survey, carried out by the João Pinheiro Foundation-an organization associated with the state government of Minas Gerais [28]. This survey, based on a sample of 7,500 households with about 24,000 respondents, is undertaken on a regular basis and is designed to be representative of the non-institutionalized population residing in the Belo Horizonte Metropolitan Region. The sampling design is two staged: strata are identified at the census tract level and households within census tracts are the primary sampling unit. More details on the survey design can be found in prior publications and online [29-31].

Of the total households selected, 5,802 (77.3\%) participated in the survey. All residents in the sampled households over the age of 20 were eligible to participate in the health supplement via face to face interview, making a total of 12,979 participants $[27,28]$. The health supplement was reviewed and approved by the IRB of the Instituto de Pesquisas René Rachou da Fundação Oswaldo Cruz in Belo Horizonte, Minas Gerais.

Our dependent variable was the respondents' selfreport to the question, "Have you felt yourself to be the victim of any type of discrimination?" Respondents were then read a list of options, including "when seeking healthcare services, in the work environment, in the family, in social occasions among friends or in public places, and/or in other situations". An indicator variable, termed "any discrimination" was developed to capture whether the respondent replied yes to any of these subcategories. This measure was used because of its sensitivity, that is, its ability to capture the widest experience of different types of perceived discrimination [32]. We used this broad measure because our objective was to obtain an indication of the prevalence of multiple forms of discrimination and associated factors in the Belo Horizonte metropolitan region.

The main exposure variables included the respondents' self-reported skin color, based on those in the Brazilian census categories that include: white (branca), black (preta), brown (parda), and yellow (amarela). The latter category (amarela) had only 11 respondents and was dropped from analyses. There were no respondents who identified themselves as "indigenous", although 38 individuals had missing values for skin color and were also dropped from analyses. Other exposure variables were gender (male/female), and a set of measures of socioeconomic status including education (categorized into less than 4 years, 4-7 years, 8-12 years, and 12 or more years and which correspond to less than primary school, completed primary school, completed high school, and some college) and household wealth. We use household wealth as a proxy for income to better capture extremes 
on both ends of the income distribution. To do this, we created a household wealth index by performing principal component analysis on a list of 12 household goods. The analysis resulted in only one factor with an Eigenvalue over 1, so this factor was extracted and the resulting score was divided into quintiles [33,34]. We also measured individual's sense of relative social position using the MacArthur scale of subjective social status [35].

Other descriptive variables include age and a composite measure of poor health status. Because of collinearity among health indicators, we created a composite measure based on principal component analysis of reports of poor/very poor self-rated health, number of the last 30 days spent in poor mental and/or physical health, and history of medical diagnosis of one or more of a list of 8 common chronic conditions. Only one factor had an Eigenvalue over 1, so it was extracted. Given its distribution, this factor, which we term "poor health score", was divided into tertiles. The lowest tertile, representing "few health problems", is used as the reference group.

Two contextual variables were also analyzed. The first captures whether the person resides in the city of Belo Horizonte or one of its surrounding municipalities. The second, termed "social trust" is used to capture aspects of the individual's social environment. It is composed of respondents' answers to whether "most people can be trusted" and whether "most people would take advantage of you if they could". The variable is coded as 1 (i.e. the respondent exhibits low social trust) if the person responded negatively to the first question and positively to the second.

Bivariate analyses of differences in proportions were based on design-corrected Pearson (F-tests) between the population proportion and each sub-group. Multivariable analyses use logistic regression (since the main outcome is relatively infrequent) to assess the magnitude and statistical significance of a set of correlates thought to be associated with experience of discrimination. Results are presented as a series of nested models to illustrate the effect of adding additional sets of variables to the models. All main explanatory variables were tested for interactions. Only one set of interaction terms was statistically significant (skin color and residence in Belo Horizonte) and was included in the final analyses. Based on results of the full models, adjusted probabilities were calculated using the Stata statistical package version 12's "margins" command [36]. Results are displayed graphically to visualize different combinations of variables. Adjusted probabilities are calculated based on the previously fitted full multivariable model, by setting a variable of interest at a specific value and then calculating the values of the outcome variable across a specified range, while all other covariates are held at their mean [36]. All analyses (including predicted probabilities) control for the complex sample using Stata's "svy" commands. Standard errors are corrected for the two stage sample, first by stratum (census tract), then by primary sampling unit (household) and incorporate sample weights. Adjustment of standard errors for household clustering is particularly important given that all adults aged 20 years and over in the selected households were interviewed and these individuals (the mean number of individuals interviewed per household was 2.2 and varied from 1 to 8 ) are likely to be more similar to each other than to people from other households [37]. Full models were tested for collinearity, which was found to be very low (the average Variance Inflation Factor was $<1.5$ ).

\section{Results}

Table 1 shows the distribution of all variables by selfreported skin color. Nearly $49 \%$ identified as white, $43 \%$ as pardo or brown, and $8 \%$ as black. There were few differences in sex or age according to skin color group. Those in the white group were less likely to report less than 4 years of schooling and more likely to report having 12 or more years than the general population. Those in the black group had nearly double the population average of those with under 4 years and about $60 \%$ fewer adults with 12 or more years of education than the general population. The pardo group had larger numbers of individuals in the middle of the educational distribution. The white group had fewer members in the lowest wealth quintile, while the black group had the highest, followed by the pardo group. In terms of health status, the black group had the lowest proportion of those in the category with the fewest health problems and the pardo group had higher than average proportion in that group.

Subjective social status was lowest in the black group, while the white and pardo groups were not different from the population average. There were no differences in levels of social trust among the groups. Whites were more likely and black and pardo respondents less likely to live within the city of Belo Horizonte.

Reports of discrimination also varied by group, with the highest report (15\%) among those who identified as black, nearly double the population average. Members of this group also reported higher instances of each specific type of discrimination than the average, except for discrimination in seeking healthcare, which did not differ by skin color group.

Table 2 presents results of multiple logistic regression of report of any type of discrimination. Those who identify as black have a consistently higher odds of reporting discrimination--nearly twice that of their white counterparts. Women are also consistently more likely to report 
Table 1 Descriptive statistics, by self-reported skin color (\%)

\begin{tabular}{|c|c|c|c|c|}
\hline & White $^{1}$ & Black & Pardo (brown) & Total \\
\hline N (unweighted) & 6,527 & 1,121 & 5,282 & 12,930 \\
\hline \% (weighted) & 48.86 & 8.35 & 42.78 & 100.00 \\
\hline Aged $20-29$ years & 23.76 & 24.56 & 26.80 & 25.13 \\
\hline 30-39 years & 21.11 & 21.49 & 22.99 & 21.95 \\
\hline 40-49 years & 19.75 & 19.16 & 20.26 & 19.92 \\
\hline $50-59$ years & 15.78 & 16.49 & 15.79 & 15.84 \\
\hline $60+$ years & 19.60 & 18.30 & $14.16^{*}$ & 17.17 \\
\hline Male & 45.58 & 43.75 & 47.71 & 46.34 \\
\hline Female & 54.42 & 56.25 & 52.29 & 53.66 \\
\hline Schooling (<4 years) & $6.35^{*}$ & $16.34^{*}$ & 9.42 & 8.5 \\
\hline 4-7 years & $18.22^{*}$ & $31.66^{*}$ & $27.72^{*}$ & 23.41 \\
\hline $8-12$ years & 44.61 & 43.75 & $50.6^{*}$ & 47.10 \\
\hline $12+$ years & $30.82^{*}$ & $8.24^{*}$ & $12.26^{*}$ & 20.99 \\
\hline$>$ lowest income quintile & $86.75^{*}$ & $69.67^{*}$ & $76.05^{*}$ & 80.75 \\
\hline lowest income quintile (poor) & $13.25^{*}$ & $30.33^{*}$ & $23.95^{*}$ & 19.25 \\
\hline Few health problems & 61.72 & $57.53^{*}$ & $66.99^{*}$ & 63.63 \\
\hline Some health problems & 25.94 & 28.59 & 22.58 & 24.72 \\
\hline Many health problems & 12.34 & 13.88 & 10.43 & 11.65 \\
\hline Highest social position (top 2 tertiles) & 66.77 & $52.20^{*}$ & 62.56 & 63.75 \\
\hline Lowest social position (lowest tertile) & 35.30 & $47.80^{*}$ & 37.44 & 36.25 \\
\hline Highest social trust (top 2 categories) & 80.88 & 85.39 & 85.37 & 83.18 \\
\hline Lowest social trust (versus top 2 categories) & 19.12 & 14.61 & 14.63 & 16.82 \\
\hline Non $\mathrm{BH}$ city resident & $35.37^{*}$ & $48.76^{*}$ & $44.72^{*}$ & 40.49 \\
\hline $\mathrm{BH}$ city resident & $64.63^{*}$ & $51.24^{*}$ & $55.28^{*}$ & 59.51 \\
\hline No report of discrimination & 91.60 & $84.85^{*}$ & 92.44 & 91.39 \\
\hline Reported discrimination (any) & 8.40 & $15.15^{*}$ & 7.56 & 8.61 \\
\hline In work place & 3.32 & $6.50^{*}$ & 3.00 & 3.45 \\
\hline In seeking medical care & 1.99 & 2.18 & 2.05 & 2.03 \\
\hline In the family & 1.40 & $2.68^{*}$ & 1.24 & 1.44 \\
\hline In social occasions & 4.21 & $9.71^{*}$ & 3.38 & 4.32 \\
\hline In other situations & 2.17 & $4.73^{*}$ & 2.20 & 2.40 \\
\hline
\end{tabular}

Numbers are design-corrected weighted proportions.

Note that "amarelo" and "unknown" skin color categories dropped due to low prevalence $(<1 \%)$

*= significant difference from "total" category $(p<0.05)$.

discrimination than men. Compared to those in their 20s, people in their 30s are more likely to report experiences of discrimination. Once health status is included in the model, people in their 60's or older were less likely to report discrimination than those in their 20's.

Poverty and educational attainment were not associated in any model with discrimination. Those with the lowest subjective social status and those with low social trust were about one-fifth more likely to report discrimination than those with higher levels of these measures. The presence of health problems was consistently associated with higher reports of discrimination. Individuals with the highest levels of health problems had much higher odds of reporting discrimination than those with the fewest health problems. Finally, residence in the city of Belo Horizonte had a negative (protective) relationship for whites, but a positive relationship for blacks.

Table 3 breaks down the discrimination measure into its distinct types as presented in the questionnaire. For each discrimination category, higher odds were reported among people who identify as black, except in the case of discrimination in seeking medical care, which was not significant for any group. The association with age detected in the overall measure of any discrimination 
Table 2 Self-report of ANY form of discrimination $(n=12,213)$

\begin{tabular}{|c|c|c|c|c|c|c|c|c|c|}
\hline & Model 1 & Model 2 & Model 3 & Model 4 & Model 5 & Model 6 & Model 7 & Model 8 & Model 9 \\
\hline Black skin color & $1.95^{* * *}$ & $1.94^{* * *}$ & $1.93^{* * *}$ & $1.9^{* * *}$ & $1.89^{* * *}$ & $1.93^{* * *}$ & $1.91^{* * *}$ & $1.91^{* * *}$ & $1.55^{*}$ \\
\hline (versus white) & $1.53,2.48$ & $1.53,2.48$ & $1.52,2.47$ & $1.48,2.44$ & $1.46,2.45$ & $1.48,2.53$ & $1.46,2.50$ & $1.46,2.50$ & $1.10,2.18$ \\
\hline Brown skin color & 0.89 & 0.89 & 0.89 & 0.88 & 0.88 & 0.93 & 0.94 & 0.94 & $0.71^{*}$ \\
\hline (versus white) & $0.76,1.05$ & $0.75,1.05$ & $0.76,1.05$ & $0.75,1.04$ & $0.74,1.04$ & $0.79,1.11$ & $0.79,1.11$ & $0.79,1.11$ & $0.54,0.93$ \\
\hline 30-39 years old & & $1.4^{* *}$ & $1.39^{* *}$ & $1.39^{* *}$ & $1.4^{* *}$ & $1.3^{*}$ & $1.31^{*}$ & $1.31^{*}$ & $1.33^{*}$ \\
\hline (versus 20-29 years) & & $1.13,1.74$ & $1.12,1.73$ & $1.12,1.73$ & $1.12,1.74$ & $1.05,1.62$ & $1.05,1.64$ & $1.05,1.63$ & $1.07,1.66$ \\
\hline $40-49$ & & $1.42^{* *}$ & $1.41^{* *}$ & $1.42^{* *}$ & $1.42^{* *}$ & 1.16 & 1.18 & 1.18 & 1.19 \\
\hline (versus 20-29 years) & & $1.15,1.76$ & $1.14,1.75$ & $1.15,1.75$ & $1.15,1.77$ & $0.94,1.45$ & $0.95,1.46$ & $0.95,1.46$ & $0.95,1.47$ \\
\hline $50-59$ & & $1.34^{* *}$ & $1.32^{*}$ & $1.33^{*}$ & $1.34^{*}$ & 0.93 & 0.94 & 0.94 & 0.96 \\
\hline (versus 20-29 years) & & $1.07,1.67$ & $1.06,1.65$ & $1.07,1.66$ & $1.06,1.69$ & $0.72,1.19$ & $0.74,1.21$ & $0.74,1.21$ & $0.75,1.22$ \\
\hline $60+$ & & 1.1 & 1.07 & 1.07 & 1.05 & $0.61^{* * *}$ & $0.62^{* *}$ & $0.62^{* *}$ & $0.63^{* *}$ \\
\hline (versus 20-29 years) & & $0.87,1.40$ & $0.84,1.36$ & $0.84,1.36$ & $0.80,1.38$ & $0.45,0.81$ & $0.46,0.83$ & $0.46,0.83$ & $0.46,0.84$ \\
\hline Female & & & $1.31^{* * *}$ & $1.31^{* * *}$ & $1.31^{* * *}$ & $1.22^{* *}$ & $1.21^{* *}$ & $1.21 * *$ & $1.21^{* *}$ \\
\hline (versus male) & & & $1.16,1.49$ & $1.16,1.49$ & $1.15,1.49$ & $1.07,1.39$ & $1.06,1.38$ & $1.06,1.38$ & $1.06,1.38$ \\
\hline Poorest wealth quintile & & & & 1.11 & 1.11 & 1.03 & 1.01 & 1.01 & 1.01 \\
\hline (versus top 4 quintiles) & & & & $0.91,1.35$ & $0.90,1.36$ & $0.84,1.28$ & $0.82,1.24$ & $0.82,1.24$ & $0.82,1.25$ \\
\hline 4-7 years schooling & & & & & 0.85 & 0.95 & 0.96 & 0.96 & 0.96 \\
\hline (versus < 4 years) & & & & & $0.65,1.11$ & $0.72,1.25$ & $0.73,1.26$ & $0.73,1.26$ & $0.73,1.27$ \\
\hline 8-11 years schooling & & & & & 0.9 & 1.08 & 1.12 & 1.11 & 1.13 \\
\hline (versus < 4 years) & & & & & $0.68,1.19$ & $0.81,1.44$ & $0.84,1.49$ & $0.84,1.48$ & $0.85,1.49$ \\
\hline $12+$ years schooling & & & & & 0.9 & 1.1 & 1.17 & 1.17 & 1.23 \\
\hline (versus < 4 years) & & & & & $0.65,1.24$ & $0.79,1.54$ & $0.84,1.64$ & $0.83,1.64$ & $0.88,1.67$ \\
\hline Some health problems & & & & & & $2.29 * * *$ & $2.29^{* * *}$ & $2.29 * * *$ & $2.27^{* * *}$ \\
\hline (versus few) & & & & & & $1.91,2.75$ & $1.90,2.75$ & $1.90,2.75$ & $1.89,2.72$ \\
\hline Many health problems & & & & & & $4.98^{* * *}$ & $4.94^{* * *}$ & $4.94^{* * *}$ & $4.97^{* * *}$ \\
\hline (versus few) & & & & & & $4.08,6.08$ & $4.05,6.03$ & $4.05,6.02$ & $4.07,6.07$ \\
\hline Lowest subjective social status & & & & & & & $1.23^{* *}$ & $1.23^{* *}$ & $1.23^{*}$ \\
\hline (versus highest 2 tertiles) & & & & & & & $1.05,1.45$ & $1.05,1.45$ & $1.05,1.44$ \\
\hline Lowest social trust & & & & & & & $1.27^{*}$ & $1.27^{*}$ & $1.27^{*}$ \\
\hline (versus highest 2 categories) & & & & & & & $1.05,1.54$ & $1.05,1.54$ & $1.05,1.54$ \\
\hline BH city & & & & & & & & 1.02 & $0.79^{*}$ \\
\hline (non-BH city dweller) & & & & & & & & $0.86,1.20$ & $0.63,1.00$ \\
\hline BH city* Black & & & & & & & & & $1.79^{* *}$ \\
\hline (versus non $\mathrm{BH}$, white) & & & & & & & & & $1.21,2.64$ \\
\hline BH city* Brown & & & & & & & & & 0.91 \\
\hline (versus non $\mathrm{BH}$, white) & & & & & & & & & $0.72,1.14$ \\
\hline
\end{tabular}

Figures are odds ratios and $95 \%$ confidence intervals from logistic regression. Results are adjusted for complex sample design and includes sample weights. ${ }^{*} p<0.05 ;{ }^{* *} p<0.01 ;{ }^{* * *} p<0.001$.

was not present in any systematic way. Schooling exhibited little association with any specific form of discrimination. In the case of discrimination experienced while seeking medical care, both women and those in the lowest income quintile report higher odds than their reference categories. The relationship between poor health and discrimination was positive and consistent for each discrimination type and was highest for those in the worst health. Low subjective social status and low social trust were of similar magnitude and positively associated with discrimination, except in the case of medical care and in "other" occasions. Finally, the interaction of residence in Belo Horizonte and black skin color was positive and significant for all categories except for medical care. 
Table 3 Correlates of TYPE of discrimination reported $(n=12,213)$

\begin{tabular}{|c|c|c|c|c|c|}
\hline & In Health services & At work & In the family & In Social occasions & In Other situations \\
\hline Black skin color & 0.71 & $1.75^{*}$ & $2.41^{*}$ & $1.96^{* * *}$ & 1.31 \\
\hline (versus white) & $0.33,1.55$ & $1.10,2.81$ & $1.16,5.02$ & $1.32,2.92$ & $0.68,2.51$ \\
\hline Brown skin color & 0.81 & 0.71 & 1.03 & $0.5^{* * *}$ & 0.75 \\
\hline (versus white) & $0.49,1.31$ & $0.48,1.04$ & $0.55,1.96$ & $0.35,0.73$ & $0.46,1.22$ \\
\hline 30-39 years old & 1.45 & $1.47^{*}$ & 0.92 & 1.11 & 1.34 \\
\hline (versus 20-29 years) & $0.94,2.23$ & $1.07,2.01$ & $0.57,1.48$ & $0.83,1.50$ & $0.93,1.94$ \\
\hline $40-49$ & 1.1 & $1.43^{*}$ & 1.05 & 1.07 & 0.88 \\
\hline (versus 20-29 years) & $0.70,1.72$ & $1.05,1.96$ & $0.63,1.74$ & $0.80,1.43$ & $0.58,1.34$ \\
\hline $50-59$ & 1.14 & 1.13 & 1.11 & 0.82 & 1.01 \\
\hline (versus 20-29 years) & $0.71,1.85$ & $0.78,1.64$ & $0.64,1.95$ & $0.58,1.16$ & $0.65,1.59$ \\
\hline $60+$ & 0.8 & $0.62^{*}$ & 0.55 & $0.62^{*}$ & 0.6 \\
\hline (versus 20-29 years) & $0.45,1.41$ & $0.39,1.00$ & $0.29,1.03$ & $0.42,0.93$ & $0.34,1.04$ \\
\hline Female & $1.33^{*}$ & 1.01 & 1.24 & 1.01 & 1.06 \\
\hline (versus male) & $1.01,1.76$ & $0.83,1.23$ & $0.91,1.70$ & $0.84,1.21$ & $0.83,1.35$ \\
\hline Poorest wealth quintile & $1.62^{*}$ & 1.15 & 1.08 & 0.89 & 0.81 \\
\hline (versus top 4 quintiles) & $1.08,2.42$ & $0.86,1.52$ & $0.69,1.68$ & $0.66,1.18$ & $0.56,1.18$ \\
\hline 4-7 years schooling & 1.07 & 0.98 & 1.22 & 1.02 & 1.02 \\
\hline (versus < 4 years) & $0.67,1.72$ & $0.62,1.56$ & $0.72,2.07$ & $0.70,1.50$ & $0.62,1.68$ \\
\hline 8-11 years schooling & 1.28 & 1.59 & 1.16 & 1.13 & 1.04 \\
\hline (versus < 4 years) & $0.76,2.17$ & $0.99,2.56$ & $0.63,2.14$ & $0.75,1.69$ & $0.62,1.74$ \\
\hline $12+$ years schooling & 1 & $1.97^{*}$ & 1.19 & 1.16 & 1 \\
\hline (versus < 4 years) & $0.50,2.00$ & $1.15,3.36$ & $0.55,2.61$ & $0.73,1.85$ & $0.53,1.89$ \\
\hline Some health problems & $1.56^{*}$ & $2.15^{* * *}$ & $2.33^{* * *}$ & $1.95^{* * *}$ & $1.87^{* * *}$ \\
\hline (versus few) & $1.07,2.28$ & $1.63,2.83$ & $1.58,3.44$ & $1.50,2.53$ & $1.31,2.67$ \\
\hline Many health problems & $4.45^{* * *}$ & $4.11^{* * *}$ & $6.24^{* * *}$ & $4.32^{* * *}$ & $3.99 * * *$ \\
\hline (versus few) & $3.01,6.59$ & $3.06,5.52$ & $4.09,9.50$ & $3.32,5.62$ & $2.83,5.64$ \\
\hline Lowest social status & 1.28 & $1.43^{* *}$ & $1.5^{*}$ & $1.26^{*}$ & 1.32 \\
\hline (versus highest 2 tertiles) & $0.98,1.69$ & $1.15,1.79$ & $1.07,2.11$ & $1.01,1.57$ & $0.98,1.79$ \\
\hline Lowest social trust & 1.1 & $1.48^{* *}$ & $1.55^{*}$ & $1.35^{*}$ & 1.04 \\
\hline (versus highest 2 categories) & $0.76,1.58$ & $1.14,1.91$ & $1.04,2.31$ & $1.04,1.76$ & $0.72,1.50$ \\
\hline BH city & 0.79 & 0.82 & 1.58 & 0.75 & 0.93 \\
\hline (non-BH city dweller) & $0.51,1.22$ & $0.59,1.14$ & $0.91,2.72$ & $0.55,1.03$ & $0.59,1.47$ \\
\hline BH city* Black & 0.82 & $1.97^{*}$ & $2.32^{*}$ & $2.12^{* *}$ & $2.86^{* * *}$ \\
\hline (versus non $\mathrm{BH}$, white) & $0.39,1.75$ & $1.09,3.57$ & $1.07,5.03$ & $1.34,3.37$ & $1.58,5.17$ \\
\hline BH city* Brown & 0.9 & 1.02 & 1.43 & 0.85 & 1.19 \\
\hline (versus non $\mathrm{BH}$, white) & $0.58,1.38$ & $0.74,1.41$ & $0.79,2.56$ & $0.63,1.16$ & $0.78,1.82$ \\
\hline
\end{tabular}

Figures are odds ratios and $95 \%$ confidence intervals from logistic regression. Results are adjusted for complex sample design and include sample weights. ${ }^{*} \mathrm{p}<0.05 ;{ }^{* *} \mathrm{p}<0.01 ;{ }^{* * *} \mathrm{p}<0.001$.

Figure 1 shows how the predicted probabilities for reporting discrimination vary by skin color, age group, and sex, once all other variables are set at their mean. It shows that for every age group, people who identify as black are about twice as likely to report experiencing discrimination and that there is little difference between reports among those identified as white or pardo. There is a nonlinear relationship with age, where probabilities peak at age 30-39, then decline thereafter. The error bars show that the predicted probability of reporting some form of discrimination among people who identify as black (with the exception of those age 60+) is significantly higher than those in the white or brown groups $(\mathrm{p}<0.05)$. This relationship is similar for each sex, albeit 


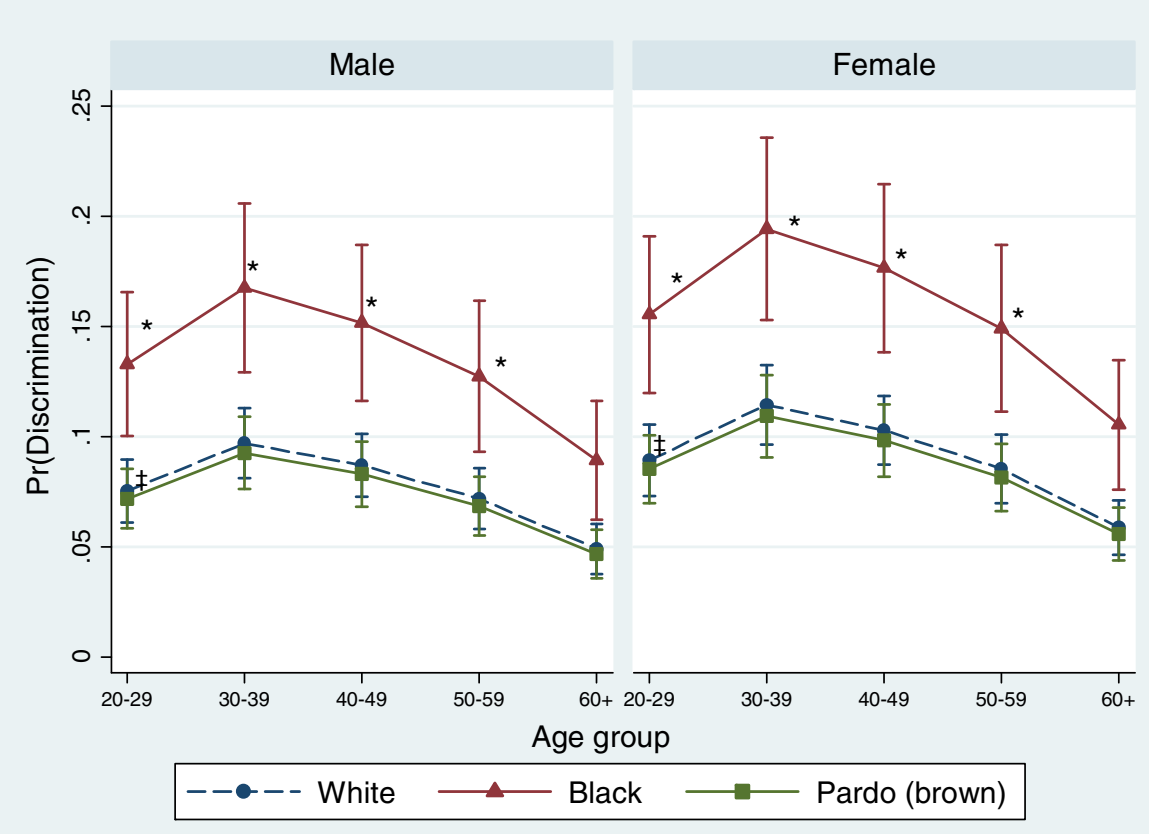

Figure 1 Predicted probability of reporting any discrimination by age group, skin color, and gender. Predicted probabilities of perceived discrimination from logistic regression controlling for variables presented in the figure in addition to schooling, health problems, social status, social trust, and $\mathrm{BH}$ city residence, all held at their mean. * Difference is statistically significant from reference category ( $\neq)$ at the $p<0.05$ level.

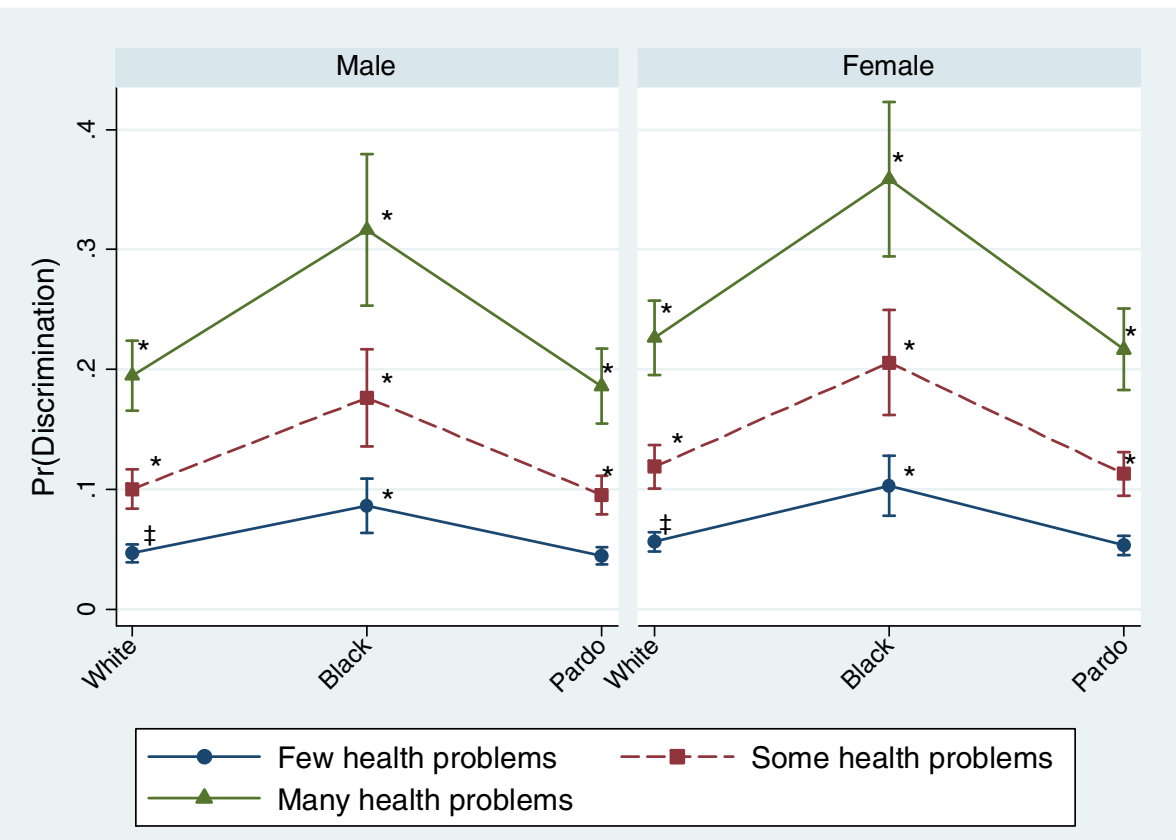

Figure 2 Predicted probability of reporting any discrimination by health problem, skin color, and gender. Predicted probabilities of perceived discrimination from logistic regression controlling for variables presented in the figure in addition to age, schooling, social status, social trust, and BH city residence, all held at their mean. * Difference is statistically significant from reference category ( $\neq$ ) at the $p<0.05$ level. 
more pronounced for women. The highest predicted values of perceived discrimination were among black women aged 30-39 (19\%) and 40-49 years (17.5\%).

Figure 2 illustrates relationships among skin color, gender, and health problems. It shows that discrimination reports are highest among those who identify as black, those who report many health problems, and higher for women as compared to men. These differences are statistically significant $(\mathrm{p}<0.05)$ when compared to the references group (people who identify as white and have few health problems) among both men and women. The highest predicted probabilities of perceived discrimination were among black men and women in poor health (31\% and $35 \%$, respectively).

\section{Discussion}

This study found that in a large metropolitan area, discrimination is strongly associated with a number of individual and contextual characteristics, including skin color, gender, age, and social position. An important finding is the strong and consistent association between being in poor health status and experiencing discrimination. Place also matters. Residence in Belo Horizonte was protective for whites, but was a risk factor for people identifying as black.

The prevalence of overall discrimination (8.6\%) was slightly lower than reported in other studies, which varied from $12 \%$ among residents of São Paulo to $13 \%$ in a nationally-representative opinion poll from 2003 [19,38]. Some of this difference may be due to the fact that each study posed questions about discrimination differently and may also represent regional differences since our study took place in a single metropolitan area.

Reports of discrimination in healthcare settings in this study were within the low end of the range reported elsewhere, which ranged from about 1\% (based on skin color) to $13 \%$ (based on economic status) of participants who received outpatient and inpatient care, respectively. [20] In studies of other national health systems, experience of perceived prior discrimination in healthcare settings may lead to subsequent underuse of some types of healthcare services, and may also alter the way medical advice is interpreted and acted upon [3]. In our study, multivariable models show that identification as "black" was associated with higher odds of reported discrimination in all settings, except for discrimination experienced in healthcare settings-a finding consistent with other reports [22]. However, women and the poor were more likely to report having experienced discrimination in seeking healthcare-a finding that may have implications for the way the Brazilian health system tackles its ongoing process of quality improvement and "humanization", that is, making the national health service more accommodating and appropriate for its users [39].

The nonlinear association between age and discrimination requires further investigation. One explanation may be that different age cohorts experienced or perceived discrimination in different ways, or differ in their attitudes towards reporting it. It is also possible that by controlling for health problems in our models, we are capturing more directly some of the reasons why people in the older age groups may experience discriminationperhaps due to mobility limitations or other reasons associated with poor health. This interpretation is supported by the reduction of standard errors for the age 60 and over group observed before (model 5) and after (model 6) introduction of the health measures.

Our study found that people in poor health have consistently higher odds (about 5 times higher than those with very few health problems) of reporting discrimination. However, the association between poor health and discrimination while seeking medical care was not found to be any higher than in other types of settings. We expected this relationship to be more pronounced, given that people with more health problems should have had increased contact with the health system. Although we cannot establish causal relationships linking discrimination and poorer health, there is considerable evidence on this association. However, longitudinal studies in the Brazilian context are scarce [19,23,40-42]. More nuanced measures of discrimination in a longitudinal context will be necessary to tease out the complex causal relationships between discrimination and poor health in Brazil.

The finding of higher experiences of discrimination among people identifying as "black" is also consistent with other studies $[19,21]$. However, the implications of this finding need to be understood within the Brazilian context. First, as in other countries, ways of measuring and defining categories of skin color and the meanings assigned to these categories are complex social constructions. In Brazil, there is considerable evidence of how changing social attitudes towards skin color have led to increased social desirability for individuals to identify as lighter skin color [43]. At the same time, some social movements have called for wider acceptance of "black" identity and African heritage. The implication for interpreting findings from this study is that people who chose to classify themselves as "black" may be different from people with otherwise similar features who choose to categorize themselves as "brown", for example. Recent studies have shown that Brazilians tend to self-classify their skin color near the center of the color gradient, indicating a preference for the "brown" category and its association with the idea of a "mixed-race nation" [22]. The distribution of individuals who self-classified as black along the color scale may indicate either that the 
value attributed to their skin color is somehow different and/or that "black" represents a political identity adopted by some in order to indicate African ancestry and not merely the color of their skin [22]. The literature suggests that heightened racial or ethnic identification may either protect (due to decreased internalization of negative stereotypes) [44] or exacerbate (through greater vigilance and therefore enhanced awareness of discriminatory acts) the link between discrimination and health [12].

Skin color in Brazil, as in other countries, is also correlated with social class, education, income, and geography [16,45-48]. Consequently, Brazilian studies linking skin color with health outcomes have shown mixed results. In one survey, social inequalities in self-rated health and in the use of health services were not associated with race/skin color once education and economic status were controlled [22]. In another study, the association between discrimination based on skin color and poor health status was significant even after controlling for these factors [23].

The finding that traditional "objective" measures of socioeconomic status (household wealth and education) were not associated with reports of discrimination is unique. Part of this relationship may be explained by the presence of other important demographic variables (age and sex) as well as skin color in multivariable models. This study also points to the potential usefulness of subjective social status (via the MacArthur ladder) as an alternative measure of social position. Studies have shown it to be an important complement to other measures of SES [11] although to our knowledge, this is the first time it has been used in a large household health survey in Brazil.

Social trust was another consistent predictor of discrimination. There is evidence that social support may moderate the effects of discrimination on health, [49] although from this cross-sectional study we do not know if people have low trust due to past experiences of discrimination or whether people who have less trust are more likely to interpret others' actions as discriminatory or to report acts of discrimination more frequently.

Finally, residence in the city of Belo Horizonte was found to be protective for whites, but a risk factor for people identifying as black. Explanations for this relationship could be due to population density (greater exposure to people may increase odds of experiencing discrimination), but if this were the case we would have expected to have found a significant interaction between urban residence and gender (which we did not). Other explanations such as racial residential segregation (and important explanatory factor in studies conducted in the United States) also appear to be inadequate to explain this finding, since such concentration in Brazil is more apparent at the state and regional levels than within cities--at least within the Belo Horizonte metropolitan region [50]. The result could also be an artifact of the meaning assigned to identifying as "black", among residents in Belo Horizonte city--the largest metropolitan area in the region.

This study has several strengths and weaknesses. Perceived discrimination should have high external validity because it represents the lived experience of individuals, but it may also present an incomplete picture of reality [51]. There is some evidence that individuals may fail to acknowledge acts of discrimination in order to avoid feeling that they do not have control over situations, or may prefer not to recall or to report such situations $[52,53]$. Consequently, in this study and others, it is safe to assume that many experiences of discrimination have been underreported.

More important may be limitations on our ability to interpret the motive behind the discrimination that respondents report. We do not know if these are isolated experiences or long-term processes. We also cannot tease out the actual motivation for the discriminatory act, although, there does not appear to be evidence that any one type of discrimination is necessarily more severe in its health effects than any other type [12]. Further Brazilian studies should test more specific measures of discrimination in order to better characterize the relationship between different types and motivations for unfair treatment and their potentially differential effects on health and well-being [25].

In conclusion, we have found that experiences of discrimination are prevalent in a large urban metropolitan region in a multiracial society that has wide-reaching social inequalities. While skin color was an important predictor of discrimination, other characteristics, such as poor health, gender, social status, and trust were also important and powerful risk factors. Our study suggests that discussions in Brazil about discriminationboth within and outside the context of the health systemshould not be limited only to questions about race. Although racism is clearly an issue in Brazil and elsewhere, this study supports recent calls to address a wider set of interrelated factors within and across different population groups [39].

\section{Competing interests}

The authors declare that they have no competing interests.

\section{Authors' contributions}

JM and MFLC conceived the study. JM carried out data analysis and JM and PM drafted the text. All authors helped to draft and revise the manuscript and interpreted results. All authors read and approved the final manuscript.

\section{Acknowledgments}

The Second Household Health Survey of the Metropolitan Region of Belo Horizonte was funded by the Primary Care Department of the Brazilian Ministry of Health. M.F. Lima-Costa and F.A. Proietti are fellows of the Conselho Nacional de Desenvolvimento Científico e Tecnológico, Brazil 


\section{Author details}

'Dept. of Nutrition, Food Studies \& Public Health, New York University, New York, USA. ${ }^{2}$ Dept. of Social and Preventive Medicine, Federal University of Minas Gerais, Belo Horizonte, Brazil. ${ }^{3}$ René Rachou Research Institute, Oswaldo Cruz Foundation, Belo Horizonte, Minas Gerais, Brazil.

Received: 9 October 2012 Accepted: 12 December 2012

Published: 18 December 2012

\section{References}

1. Williams DR, Spencer MS, Jackson JS: Race, stress, and physical health: The role of group identity. In Self, social identity, and physical health: Interdisciplinary explorations. Edited by Contrada RJ, Ashmore RD. New York: Oxford University Press; 1999:71-100.

2. Brody GH, Kogan SM, Chen YF: Perceived discrimination and longitudinal increases in adolescent substance use: gender differences and mediational pathways. Am J Public Health 2012, 102(5):1006-1011.

3. Harris R, Cormack D, Tobias M, Yeh LC, Talamaivao N, Minster J, Timutimu R: Self-reported experience of racial discrimination and health care use in New Zealand: results from the 2006/07 New Zealand Health Survey. Am J Public Health 2012, 102(5):1012-1019.

4. Hausmann LR, Jeong K, Bost JE, Ibrahim SA: Perceived discrimination in health care and health status in a racially diverse sample. Medical care 2008, 46(9):905-914.

5. Luo Y, Xu J, Granberg E, Wentworth WM: A Longitudinal Study of Social Status, Perceived Discrimination, and Physical and Emotional Health Among Older Adults. Research on Aging 2012, 34(3):275-301.

6. Sawyer PJ, Major B, Casad BJ, Townsend SS, Mendes WB: Discrimination and the stress response: psychological and physiological consequences of anticipating prejudice in interethnic interactions. Am J Public Health 2012, 102(5):1020-1026.

7. Taylor TR, Williams CD, Makambi KH, Mouton C, Harrell JP, Cozier Y, Palmer $J R$, Rosenberg L, Adams-Campbell LL: Racial discrimination and breast cancer incidence in US Black women: the Black Women's Health Study. Am J Epidemiol 2007, 166(1):46-54.

8. Do YK, Carpenter WR, Spain P, Clark JA, Hamilton RJ, Galanko JA, Jackman A, Talcott JA, Godley PA: Race, healthcare access and physician trust among prostate cancer patients. Cancer causes \& control: CCC 2010, 21(1):31-40.

9. Schram SF, Soss J, Fording RC: Race and the Politics of welfare reform. Ann Arbor: University of Michigan Press; 2003.

10. Singh-Manoux A, Marmot MG, Adler NE: Does subjective social status predict health and change in health status better than objective status? Psychosom Med 2005, 67(6):855-861.

11. Adler NE, Epel ES, Castellazzo G, Ickovics JR: Relationship of subjective and objective social status with psychological and physiological functioning: preliminary data in healthy white women. Health psychology: official journal of the Division of Health Psychology, American Psychological Association 2000, 19(6):586-592

12. Pascoe EA, Smart Richman L: Perceived discrimination and health: a metaanalytic review. Psychol Bull 2009, 135(4):531-554.

13. Dias-da-Costa JS, Olinto MT, Bassani D, Marchionatti CR, de Bairros FS, de Oliveira ML, Hartmann M, Gabardo RM, Bennemann V, Pattussi MP. Inequalities in clinical breast examination in São Leopoldo, Rio Grande do Sul, Brazil. Cad Saude Publica 2007 Jul, 23(7):1603-1612. Portuguese.

14. Barros FC, Victora CG, Horta BL: Ethnicity and infant health in Southern Brazil. A birth cohort study. Int J Epidemiol 2001, 30(5):1001-1008.

15. Dias-da-Costa JS, Olinto MT, Bassani D, Marchionatti CR, de Bairros FS, de Oliveira ML, Hartmann M, Gabardo RM, Bennemann V, Pattussi MP: [Inequalities in clinical breast examination in Sao Leopoldo, Rio Grande do Sul, Brazil]. Cadernos de saude publica / Ministerio da Saude, Fundacao Oswaldo Cruz, Escola Nacional de Saude Publica 2007, 23(7):1603-1612.

16. Leal MC, Gama SGN, Cunha CB: Desigualdades raciais, sociodemográficas e na assistência ao pré-natal e ao parto, 1999-2001. Rev Saude Publica 2005, 39:100-107.

17. Pager $D$, Shepard $H$ : The Sociology of Discrimination: Racial Discrimination in Employment, Housing, Credit, and Consumer Markets. Annu Rev Sociol 2008, 34:181-209.

18. Williams DR, Mohammed SA: Discrimination and racial disparities in health: evidence and needed research. J Behav Med 2009, 32(1):20-47.

19. Barata RB, Ribeiro MC, Cassanti AC: Social vulnerability and health status: a household survey in the central area of a Brazilian metropolis. Cadernos de saude publica / Ministerio da Saude, Fundacao Oswaldo Cruz, Escola Nacional de Saude Publica 2011, 27(Suppl 2):S164-S175.

20. Gouveia GC, Souza WV, Luna CF, Souza-Júnior PRB, Szwarcwald CL: Health care users' satisfaction in Brazil, 2003. Cad Saude Publica 2005, 21:S109-S118

21. Bastos $\mathrm{JL}$, Gonçalves H, Faerstein E, Barros AJ: Experiências de discriminação entre universitários do Rio de Janeiro. Rev Saude Publica 2010, 44:28-38.

22. Travassos C, Laguardia J, Marques PM, Mota JC, Szwarcwald CL: Comparison between two race/skin color classifications in relation to health-related outcomes in Brazil. International journal for equity in health 2011, 10:35.

23. Faerstein E, Chor D, Werneck G, Lopes C, Lynch J, Kaplan G: Race and perceived racism, education, and hypertension among Brazilian civil servants. [abstract]. Am J Epidemiol 2004, 159:35.

24. Bastos JL, Faerstein E: Conceptual and methodological aspects of relations between discrimination and health in epidemiological studies. Cad Saude Publica 2012, 28:177-183.

25. Bastos JL, Faerstein E, Celeste RK, Barros AJD: Explicit discrimination and health: development and psychometric properties of an assessment instrument. Rev Saude Publica 2012, 46:269-278.

26. IBGE: Censo demografico de 2010. Rio de Janeiro: IBGE; 2011.

27. Lima-Costa MF, Turci MA, Macinko J: Saude dos idosos in Belo Horizonte. Belo Horizonte, Minas Gerais: Nucleo de Estudos em Saude Publica e Envelhecimento da Fundacao Oswaldo Cruz: Universidade Federal de Minas Gerais; 2012:120.

28. Fundação João Pinheiro: Centro de Estatistica e Informacao. Pesquisa de Emprego e Desemprego na Regiao metropolitana de Belo Horizonte. Belo Horizonte: Minas Gerais; Fundação João Pinheiro; 2011.

29. Lima-Costa MF, Turci M, Macinko J: Saúde dos Adultos em Belo Horizonte. Belo Horizonte, Minas Gerias: Fundação Oswaldo Cruz/UFMG; 2012.

30. Turci MA, Lima-Costa MF, Proietti FA, Cesar CC, Macinko J: Intraurban differences in the use of ambulatory health services in a large brazilian city. Journal of urban health: bulletin of the New York Academy of Medicine 2010, 87(6):994-1006.

31. Fundação João Pinheiro: Pesquisa de emprego e desemprego na Região Metropolitana de Belo Horizonte (PED/RMBH). Belo Horizonte, Minas Gerais: Fundação João Pinheiro; 2012. Retrieved November 21, 2012, from http:// www.jp.mg.gov.br/index.php/servicos/81-servicos-cei/1860-pesquisa-deemprego-e-desemprego-na-regiao-metropolitana-de-belo-horizonte.

32. Landrine H, Klonoff EA, Corral I, Fernandez S, Roesch S: Conceptualizing and measuring ethnic discrimination in health research. $J$ Behav Med 2006, 29(1):79-94.

33. Juster FT, Smith JP, Stafford F: The measurement and structure of household wealth. Labour Econ 1999, 6(2):253-275.

34. O'Donnell O, van Doorslaer E, Wagstaff A, Lindelow M: Analyzing Health Equity Using Household Survey Data. Washington, DC: The World Bank; 2008.

35. White RM: Unraveling the Tuskegee Study of Untreated Syphilis. Arch Intern Med 2000, 160(5):585-598.

36. Mitchell M: Interpreting and visualizing regression models using Stata. College Station, TX: Stata Press; 2012.

37. StataCorp: Stata: Release 12. Statistical Software. College Station, TX StataCorp LP; 2011

38. Pública NdO: Discriminacao e preconceito: Fundação Perseu Abramo (FPA): 2004.

39. Travassos $C$, Bahia $L$ : What is the agenda for combatting discrimination in the Brazilian Unified National Health System? Cadernos de saude publica I Ministerio da Saude, Fundacao Oswaldo Cruz, Escola Nacional de Saude Publica 2011, 27(2):204-205.

40. Williams DR: Race, health, and health care. St Louis Univ Law J 2003, 48(1):13-35.

41. Williams DR, Neighbors HW, Jackson JS: Racial/ethnic discrimination and health: findings from community studies. Am J Public Health 2003, 93(2):200-208

42. Wyatt SB, Williams DR, Calvin R, Henderson FC, Walker ER, Winters K: Racism and cardiovascular disease in African Americans. Am J Med Sci 2003, 325(6):315-331.

43. Telles EE: Race in Another America: The Signficance of Skin Color in Brazil. Princeton, NJ: Princeton University Press; 2004.

44. Mossakowski KN: Coping with perceived discrimination: does ethnic identity protect mental health? J Health Soc Behav 2003, 44(3):318-331 
45. Lopes F, Buchalla CM, Ayres JRCM: Mulheres negras e não-negras e vulnerabilidade ao HIV/Aids no estado de São Paulo, Brasil. Rev Saude Publica 2007, 41:39-46.

46. Simão $A B$, Miranda-Ribeiro $P$, Caetano AJ: O recorte raça/cor e a saúde reprodutiva em Belo Horizonte e Recife: uma análise exploratória sobre a realização de consultas ginecológicas, 2002. Belo Horizonte, MG: UFMG; 2004.

47. Cacciamali MC, Hirata Gl: A influência da raça e do gênero nas oportunidades de obtenção de renda - uma análise da discriminação em mercados de trabalho distintos: Bahia e São Paulo. Estudos Econômicos (São Paulo) 2005, 35:767-795.

48. Heringer R: Desigualdades raciais no Brasil: síntese de indicadores e desafios no campo das políticas públicas. Cad Saude Publica 2002, 18:S57-S65.

49. Noh S, Kaspar V: Perceived discrimination and depression: moderating effects of coping, acculturation, and ethnic support. Am J Public Health 2003, 93(2):232-238

50. White K, Haas JS, Williams DR: Elucidating the role of place in health care disparities: the example of racial/ethnic residential segregation. Health Serv Res 2012, 47(3 Pt 2):1278-1299.

51. Pager D: Medir a discriminação. Tempo Social 2006, 18:65-88.

52. Ruggiero KM, Taylor DM: Why minority group members perceive or do not perceive the discrimination that confronts them: the role of selfesteem and perceived control. J Pers Soc Psychol 1997, 72(2):373-389.

53. Kressin NR, Raymond KL, Manze M: Perceptions of race/ethnicity-based discrimination: a review of measures and evaluation of their usefulness for the health care setting. J Health Care Poor Underserved 2008, 19(3):697-730

doi:10.1186/1475-9276-11-80

Cite this article as: Macinko et al:: Who experiences discrimination in Brazil? Evidence from a large metropolitan region. International Journal for Equity in Health 2012 11:80.

\section{Submit your next manuscript to BioMed Central and take full advantage of:}

- Convenient online submission

- Thorough peer review

- No space constraints or color figure charges

- Immediate publication on acceptance

- Inclusion in PubMed, CAS, Scopus and Google Scholar

- Research which is freely available for redistribution 